Copyright (C) 2015 by Academic Publishing House Researcher

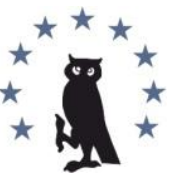

Published in the Russian Federation

European Researcher

Has been issued since 2010.

ISSN 2219-8229

E-ISSN 2224-0136

Vol. 91, Is. 2, pp. 104-113, 2015

DOI: 10.13187/er.2015.91.104

www.erjournal.ru

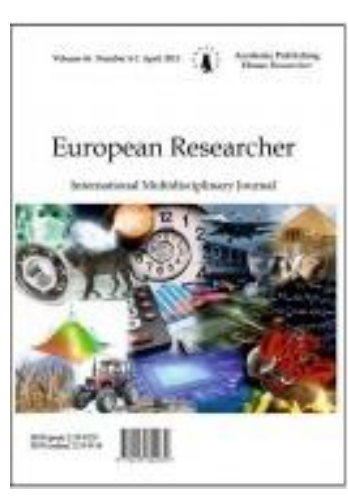

UDC 330(075.8)

\title{
Managerial Accounting as a Conceptual Basis of Integrated Management System in Small Businesses (Kazakhstan's Agro-Industrial Sector)
}

Sandugash M. Tokenova

Kazakh Agro-Technical University named by S.Seifullin, Kazakhstan

Senior Lecturer, Department of Accounting and Audit Faculty of Economics

010000, Astana city, Sh Kudayberdiuly street, flat 320

E-mail: idt12@mail.ru

\section{Abstract}

The article consideres the modern scientific approaches to the integration of management systems, interpretation of the concepts of managerial accounting and understanding of management and accounting in small businesses. The article presents the main results of the analysis of Kazakhstan's agro-industrial sector problems, ways of their solution, based on international experience and the characteristics of Kazakhstan's small business entity. There is presented the authors' vision of ways to enhance the competitiveness of small farms.

Keywords: managerial accounting; integrated management system; small business; agroindustrial sector; supply chains; the competitiveness of small farms.

\section{Введение}

Наблюдаемое в настоящее время в казахстанском агропромышленном комплексе (АПК) противоречие между уровнем управления и финансового учёта на крупных /средних предприятиях и в субъектах малого предпринимательства. Это "реальное противоречие, требующее своего разрешения» [19] является препятствием: а) интеграции малого бизнеса (МБ) в производственно-сбытовые цепочки АПК и б) повышению конкурентоспособности предприятий МБ, входящих в АПК.

\section{Анализ интеграции систем менеджмента и различные подходы к трактовке концепции управленческого учёта \\ 1. Интеграция систем менеджмента}

Точно так же, как в языках многих малых народов Севера нет понятия снега «вообще» - а есть два десятка слов для обозначения снега «только что выпавшего», «тающего», «покрытого ледяной коркой» и т.д. - в английском языке различные аспекты управления обозначаются разными терминами. Management - это не управление «вообще», а «умение принимать управленческие решения, основанное на бережном, осторожном и внимательном отношении к объекту управления, на максимальном учёте и использовании в процессе управления его специфических особенностей» [45] - тогда как управление организацией, основанное на приоритетности учёта особенностей не объекта, а субъекта 
управления обозначается совсем другими терминами (governance, administration, direction). [31]

T.е. менеджер - это специалист, использующий различные подходы к представлению объекта управления как некой совокупности проектов, рисков, стратегий, человеческих ресурсов, знаний, показателей качества, финансовых показателей и т.д. Отсюда - множество очень разных систем менеджмента и специализаций менеджеров. [32]

В 1990-х гг. в контексте проблемы снижения издержек компаний на внедрение международных стандартов менеджмента во всём мире получила распространение идея объединения разных систем менеджмента в единую интегрированную систему. Изначально такая интеграция ограничивалась разработкой на предприятиях единой терминологии и документооборота при поэлементном совмещении требований международных стандартов менеджмента качества (ИСО 9001), профессиональной безопасности и охраны труда (OHSAS 18001), экологической безопасности (ISO 14000), безопасности пищевой продукции (ISO 22000) и т.п. [42]

Распространение в последнее десятилетие новой формы организации корпоративного бизнеса - т.н. интегрированных корпоративных структур (ИКС), не имеющих единой организационной структуры «неформальных» бизнес-сообществ [3]. Главным характеристическим признаком и объединяющим элементом ИКС являются не структуры собственности и управления (как у холдинга), а наличие института. «Совокупности формальных и неформальных норм, относительно устойчивых по отношению к изменяющемуся поведению или интересам отдельных социально-экономических субъектов (как физических, так и юридических лиц) и их групп, регулирующих их деятельность и взаимодействие». [16]

Стремительное распространение в мировой экономике ИКС повлекло за собой дальнейшее развитие ИСМ [43]. Которые стали трактоваться как единая унифицированная система корпоративных норм и правил управления, охватывающая все аспекты деятельности всех хозяйствующих субъектов, входящих в ИКС [32]. При этом критерием включения субъектов малого предпринимательства в производственно-сбытовые цепочки ИКС становится их способность соблюдать эти нормы на практике.[4о]

\section{2. Различные подходы к трактовке концепции управленческого учёта}

Какая же из многочисленных концепций и отраслей менеджмента должна стать концептуальной, системообразующей основой таких ИСМ? Многие разработчики ИСМ остановили свой выбор на концепции управленческого учёта. В англоязычных источниках встречается её обозначение терминами «managerial accounting» [6; 41] «management accounting» [33] и «controling» [15; 35]; управленческий учёт - буквальный перевод «managerial accounting».

При этом специалиста, в чьи должностные обязанности входит ведение управленческого учёта, в англоязычном деловом обороте называют отнюдь не менеджер и не бухгалтер, а обозначают специфическим термином «контроллер» - очевидно, потому что эти три работника имеют в компании совершенно разные функциональные обязанности, это три совершенно разные специальности. О специфике деятельности менеджера мы уже написали в предыдущем разделе. Бухгалтер - это, во-первых, «счетовод» (accountant, comptroller) и. во-вторых, «хранитель книги учёта» (bookkeeper, booker). Контроллер же, образно говоря, является «переводчиком» этой «книги учёта». С «языка бухгалтеров» на «язык менеджеров и инвесторов» - точно так же, как юрист в каком-то смысле занимается «переводом» этой книги на «язык законов». Разница между бухгалтером и контроллером примерно такая же, как между лингвистом (который, например, занимается подсчётом количества метафор в книге) - и переводчиком этой книги на иностранный язык. Общее у них - только книга; всё остальное - задачи, методы, инструменты - всё совершенно разное. В большинстве бизнес-организаций контроллер постоянно не требуется, его, как адвоката, приглашают только тогда, когда у акционеров, топ-менеджеров или инвесторов компании возникает потребность в «переводе».

Возникновение в конце XIX - начала XX вв. двух взаимодополняющих концепций управления бизнес-организациями - управленческого учёта и менеджмента - как известно, было обусловлено качественным изменением методов промышленного производства. 
В XX в. непрерывное развитие процессов специализации / разделения труда между различными странами, предприятиями и работниками повлекло за собой необходимость постоянного обновления методов планирования и управления в бизнесе, разработки всё новых и новых концепций менеджмента и управленческого учёта.[27]

Поэтому с развитием корпоративного управления в XX в. управленческий учёт, который изначально трактовался, как «отрасль бухгалтерского дела, которая связана с представлением информации, используемой внутри предприятия» [6] и «ведение счетов исходя из потребностей управления»[33], постепенно преобразовывался - разрабатывались всё новые и новые методы анализа финансовых, а затем и нефинансовых показателей. [37]

В результате управленческий учёт сначала стал «концепцией управления предприятием с ориентацией на бухгалтерский учет» [30].

Затем, в 1980-х гг., стал трактоваться как:

- «набор методов и приемов, направленных на обеспечение менеджеров финансовой информацией, чтобы помочь им принимать решения и поддерживать эффективный контроль над корпоративными ресурсами» [37],

- «инструмент планирования, учета, анализа состояния дел на фирме, используемый для принятия решений на базе компьютеризированной системы сбора и обработки информации» [20],

- «современная комплексная технология управления предприятием, представляющую собой интегрированную систему информационно-аналитической и методической поддержки руководителей в процессе планирования, контроля, анализа и принятия управленческих решений по всем функциональным сферам деятельности предприятия» [21].

А к началу XXI в. стал восприниматься многими специалистами как «новая концепция управления компанией, порожденная практикой современного менеджмента» [15], как «мегасистема управления предприятием» [39], которая «интегрирует учет, планирование, маркетинг, менеджмент, финансы» [8].

В современной литературе по управленческому учёту нет единства мнений; все перечисленные нами научные трактовки имеют весьма авторитетных сторонников; каждый исследователь использует тот подход, который ему нужен для решения стоящих перед ним проблем.

При трактовке управленческого учёта как мегасистемы управления предприятием, которая интегрирует учет, планирование, маркетинг, менеджмент, финансы, совершенно естественным является выбор этой концепции в качестве системообразующей основы ИСМ.

\section{3. Особенности менеджмента и управленческого учёта в субъектах малого предпринимательства}

Во многих развитых странах на долю предприятий МБ приходится более половины ВВП. Во всём мире субъекты малого предпринимательства в последние два десятилетия вносят всё более существенный вклад в решение проблем занятости и повышения конкурентоспособности национальных экономик. МБ - это весомый и стабильный источник налогов, залогом стабильности которого является непрерывный процесс самообновления: на место неудачников постоянно приходят новые предприниматели - работает механизм естественного отбора наиболее конкурентоспособных предприятий [36].

Главные отличительные черты, определяющие специфику малого бизнеса:

- ориентация на специфические целевые группы потребителей: деятельность субъектах малого предпринимательства может быть вполне успешной благодаря наличию у него всего нескольких (нескольких десятков) постоянных клиентов; общее количество клиентов, как правило, не превышает нескольких сотен;

- глубокая личная заинтересованность управляющего собственника и выстраивание им со своими клиентами неформальных межличностных отношений [45].

При этом многие стандарты и формализованные методы менеджмента, разработанные для нужд среднего и крупного бизнеса, представляются управляющему собственнику субъекта малого предпринимательства не только непосильными, но и совершенно излишними - он ведь и так интуитивно понимает, что нужно нескольким десяткам (двумтрём сотням) клиентов, с которыми он лично хорошо знаком [31]. 
Специалисты отмечают, что методы финансового менеджмента предприятий МБ имеет неоднозначную трактовку в теории финансового анализа и слабую прикладную реализацию в управленческой деятельности [44]. Прежде всего, это объясняется значительно более низким требованиям к раскрытию информации в субъектах малого предпринимательства. Для привлечения внешних инвестиций, без которых невозможен бизнес, все крупные компании стремятся стать «публичными»; при этом используются два разных методологических принципа доступа к внутрифирменной информации: «детальное раскрытие» и «полное и справедливое раскрытие» [4]. Однако значительная часть предприятий МБ этим принципам не следует (не только у нас, но и на Западе [34]); даже действуя в рамках общепринятых международных стандартов бухгалтерского учета (GAAP) могут и сегодня довольно легко показать доход даже тогда, когда его денежные резервы иссякли. [40] Поэтому вполне естественно, что между корпорациями и субъектами малого предпринимательства имеются существенные различия в возможности доступа к ресурсам, в постановке целей, рисках и уровне ликвидности. Предприятию МБ на первых стадиях существования характерно парадоксальное сочетание наибольшего риска с наименьшей доходностью. Поэтому финансирование для развития МБ сильно затруднено [38].

Отсюда - принципиальные различия между методами управления и финансового учёта на крупных /средних предприятиях и в субъектах малого предпринимательства, проблема нашего исследования.

Цель исследования - поиск новых подходов к повышению конкурентоспособности предприятий МБ, входящих в казахстанский АПК.

\section{Результаты}

\section{1. Современное состояние и проблемы казахстанского АПК} $[13 ; 23]$

Состояние казахстанского АПК оценивается специалистами как неудовлетворительное

Объёмы продукции АПК в последние годы имеют положительную динамику - если сравнивать показатели с предыдущим, а не, например, с 1990 годом, уровень производства продукции АПК которого по очень многим позициям не достигнут до сих пор.

По сравнению с 1990 г. объем производства важнейших видов продовольствия на душу населения сократился от 4 до 50 раз. По среднедушевому потреблению жизненно важных продуктов питания современный Казахстан находится на уровне: по мясу и мясопродуктам - 1965 г., по молоку и молочным продуктам - 1958 г., по сахару - 1955 г., по растительным маслам - 1976 г., по фруктам и ягодам - 1960 г. [23]

Анализ производства и потребления продукции АПК в Казахстане показывает: несбалансированность отраслевой структуры АПК (как производства, так и переработки); неравномерность распределения по территории Казахстана производства и потребления; зависимость большинства сегментов казахстанского рынка продуктов питания от импорта [14].

В перерабатывающей отрасли АПК доминируют примитивные производственные циклы. В структуре продукции отрасли, доля которой в ВВП по сравнению с 1990 г. упала более чем вдвое, 71 \% приходится на производство муки и хлебобулочных изделий, ещё 11 \% на выпуск напитков, на все остальные виды пищевой продукции приходится только $18 \%$ [23].

Коэффициент фактического использования мощностей в перерабатывающей отрасли АПК низок и колеблется от $25 \%$ в молочной промышленности до 60 \% - в плодоовощеконсервной. Среди основных проблем перерабатывающей отрасли АПК можно назвать необеспеченность сырьём, отсутствие серьёзных инвестиций в отрасль, хронический недостаток оборотных средств, высокие процентные ставки по кредитам, неконкурентоспособность продукции по цене и качеству в сравнении с импортными аналогами [2].

В Казахстане неоднократно разрабатывались государственные программы по поддержке и развитию АПК. Однако ещё ни одна из этих программ не была полностью выполнена: так и не были достигнуты запланированные результаты «Программы развития сельскохозяйственного производства РК на 2000-2002 гг.», «Программы импортозамещения в отраслях легкой и пищевой промышленности на 2001-2003 годы», 
«Агропродовольственной программы на 2003-2005 гг.» и «Программы развития сельских территорий на 2004-2010 гг.» В программе «Агробизнес-2020», принятой в 2012 г., в очередной раз поставлены нереальные задачи [1].

Многие специалисты уверены, что ставка на приоритетное развитие малого и среднего бизнеса, как основного структурного элемента отраслей казахстанского АПК, совершенно не оправдалась. [23]

\section{2. Мировой опыт развития АПК}

В развитых странах производство, переработка и сбыт продукции АПК - это масштабный бизнес, глобальная конкуренция, ведущую роль в которой занимают транснациональные корпорации [5].

Государственное регулирование субъектов АПК - «глобальная политика»:

- сильные и богатые государства (такие как США и Китай) жёстко и бескомпромиссно защищают свои рынки и интересы национальных производителей;

- менее сильные и богатые (например, Россия) пытаются их отстаивать, но, в итоге, под давлением вынуждены соглашаться на некий компромисс;

- самые слабые и бедные страны мира получают продовольственную гуманитарную помощь, а вместе с ней - продовольственную и политическую зависимость; если их лидеры что-то делают «неправильно» (например, пытаются как-то избавится от этой зависимости) они немедленно сталкиваются с разного рода «санкциями» [17].

Главным инструментом этой глобальной конкуренции стали стандарты менеджмента безопасности и качества продукции АПК: чтобы поставить конкурентоспособную продукцию на мировые рынки, предприятиям АПК требуется сначала израсходовать огромные средства на их соблюдение. Во всём мире большинство субъектов малого предпринимательства АПК из-за нехватки средств на сертификацию своей продукции не могут включиться в глобальные производственно-сбытовые цепочки и реализуют свою продукцию на локальных рынках [9].

По мнению специалистов, субъектам малого предпринимательства АПК присущи: низкая доля заёмного капитала; низкая стоимость активов; небольшой объем средств, дополнительно мобилизуемых на рынке ссудных капиталов; низкая доля долгосрочных кредитов; относительно высокая доля товарных кредитов; широкое использование основных фондов, взятых в аренду [11].

Мировой опыт показывает:

- что большинство предприятий АПК во всех странах, формально являясь самостоятельными и независимыми субъектами рынка, тем не менее, не являются самодостаточными и инвестиционно-привлекательными, не способны развиваться на принципах самоокупаемости и самофинансирования, в полной мере и на равных участвовать в межотраслевой конкуренции;

- что основная тенденция развития предприятий АПК - создание интегрированных корпоративных образований), в состав которых входят предприятия всех звеньев производственно-сбытовой цепочки «производство (отрасли растениеводства и животноводства) - переработка (пищевая отрасль) - дистрибъюция (оптовая и розничная торговля)». [18; 24; 29]

\section{3. Особенности казахстанского малого бизнеса как субъекта предпринимательства}

Казахстану очень нужно развивать МБ. Ещё в 2005 году Президентом РК Н.А. Назарбаевым была поставлена задача по увеличению его вклада в ВВП республики к 2012 году до 40 \%. Однако, как следует из отчётов Агентства РК по статистике, до настоящего времени эта задача не выполнена. За последние десять лет доля МБ в казахстанском ВВП выросла с 17 до 32 \%, в стоимостном выражении объем продукции, выпускаемой субъектами малого предпринимательства, вырос почти в 4 раза [12].

Государственная поддержка субъектов малого предпринимательства осуществляется путём льготного кредитования в рамках программы «Дорожная карта бизнеса 2020». [25] Однако включению в программу объективно препятствует целый ряд факторов, главный из которых - недостаточный уровень раскрытия информации [10]. Казахстанский МБ, до сих 
пор преимущественно «серый»: по оценке Агентства по борьбе с экономической и коррупционной преступностью РК в 2012 году теневой оборот в Казахстане превышал \$30 млрд. (цит. по [22]). При этом речь не идёт о недобросовестности отдельных предпринимателей; причины информационной закрытости МБ имеют системный характер - административные барьеры, возникающие при осуществлении хозяйственной деятельности [26].

По мнению экспертов, в числе наиболее остро стоящих проблем МСБ ограниченность рынков сбыта, недобросовестная конкуренция, административные препоны и недостаток квалифицированных кадров. Нехватка финансовых, материальных, технологических и интеллектуальных ресурсов для модернизации, диверсификации и расширения бизнеса остается хронической проблемой малого предпринимательства [2]. По данным опросов, примерно половина казахстанских предпринимателей балансируют на грани выживания. Особенно это касается крестьянских хозяйств и индивидуальных предпринимателей, среди которых доля тех, у кого хватает средств только для подержания бизнеса (или чей бизнес находится в критическом состоянии), составляет соответственно $65 \%$ и 50 \% [7]. Поэтому не удивительно, что международные эксперты отмечают общий низкий уровень управления и финансового менеджмента в казахстанских предприятиях МБ (методы управленческого учёта в них практически не применяются) [28].

\section{Выводы}

1. В настоящее время конкурентоспособность казахстанских сельхозпредприятий МБ зависит, прежде всего, от их способности интегрироваться в производственно-сбытовые цепочки крупных компаний АПК.

2. Для её развития управление в субъектах малого предпринимательства должно удовлетворять стандартам корпоративного управления крупных предприятий, формирующих в АПК республики основные производственно-сбытовые цепочки.

Перед управляющими собственниками МБ встаёт задача внедрения на своих предприятиях ИСМ, которые должны быть, с одной стороны, удобны и понятны для восприятия менеджерами крупных предприятий АПК, а с другой, не требовать значительных расходов на их внедрение и особых компетенций от их пользователей управляющих собственников МБ.

3. В этих условиях концепция управленческого учёта и институт контроллеров могут быть использованы для организации ИСМ, обеспечивающей, образно говоря, «перевод» основных показателей и характеристик МБ $\mathrm{c}$ «языка субъектов малого предпринимательства» на «язык корпоративного управления».

Эффективным способом решения проблемы исследования может стать массовое внедрение в практику управления малых сельхозпредприятий специально разработанных ИСМ, центральным (системообразующим) элементом которых является концепция управленческого учёта.

\section{Примечания:}

1. Программа по развитию агропромышленного комплекса в Республике Казахстан на 2013-2020 годы (Агробизнес - 2020). Астана, 2012. 97 с.

2. Распоряжение Премьер-Министра Республики Казахстан от 7 декабря 2012 года № 226-p «Об утверждении Плана мероприятий по поддержке и развитию переработки сельскохозяйственной продукции и пищевой промышленности» // ИПС "Әділет", http://adilet.zan.kz/rus/docs/R1200000226

3. Белый Е.М., Рожкова Е.В., Тюлин А.Е. Интегрированные структуры в современной экономике: сущность, тенденции развития // Фундаментальные исследования. 2013. №6. C. 1482-1484. //http://www.rae.ru/fs/?section=content\&op=show_article\&article_id=10000974

4. Брегг С. Настольная книга финансового директора / Пер. с англ. 4-е изд. М.: Альпина Паблишер, 2013. 608 с.

5. Васильева Н.А. Развитие стратегического потенциала предприятий пищевой промышленности России в условиях глобальной конкуренции: методология, теория, практика: Дисс. ... д.э.н. Саратов, 2012. 404 с. 
6. Гаррисон Р., Норин Э., Брюэр П. Управленческий учет [Managerial Accounting] / Пер с анг. СПб.: Питер, 2013. 592 с.

7. Гуревич Л. Казахстанский предприниматель: самооценка собственной истории, предназначения и перспектив// Сайт Центра бизнес-информации, социологических и маркетинговых исследований BISAM Central Asia http://www.bisam.kz/ research/reports /msb.html

8. Демеуова Г.Т. Формирование и функционирование системы контроллинга в Казахстане: опыт оценки и расширение ее масштабов: Автореферат дисс. ... д.э.н. Алматы, 2010. 47 c.

9. Доклад Продовольственной и сельскохозяйственной организации ООН (ФАО) Тhe State of Food Insecurity in the World, 2013 http://www.fao.org/docrep/o18/i3434e/i3434eoo.htm

10. Доступность банковского кредитования в Казахстане Отчет по результатам изучения мнения клиентов банков, 2012 //Сайт Центра исследований Сандж http://www.sange.kz/files/8413/6022/o568/_u.pdf

11. Запорожцева Л.А. Внутренний мониторинг финансовой устойчивости сельскохозяйственных предприятий: формирование и развитие: Дисс.... к.э.н. Воронеж, 2007. 212 c.

12. Казахстан в 2013 году. Статистический сборник /под ред. А.А. Смаилова. Астана, 2014. 484 c.

13. Кайгородцев А.А. Экономическая и продовольственная безопасность Казахстана. Вопросы теории, методологии, практики: монография. Усть-Каменогорск: Медиа-Альянс, 2006. $440 \mathrm{c}$.

14. Камински Б., Митра С. Клубок шелка: безграничные базары и приграничная торговля в Центральной Азии. Всемирный Банк, 2012. 132 с.

15. Карминский А. М., Фалько С. Г., Жевага А. А., Иванова Н. Ю. Контроллинг. М.,: Форум, 2013. 336 c.

16. Клейнер Б.Г. Эволюция институциональных систем. М.: Наука, 2009. 240 с. с. 20.

17. Костенкова В.Г. Продвижение на рынке современных продуктов пищевой промышленности в условиях широкомасштабной экспансии импортных товаров// Вестник удмуртского университета. 2009. № 2. с. 63-68

18. Май-Борода Г.Н. Потенциал интеграционных образований как объектов управления в агропромышленном комплексе: Дисс. ... к.э.н. Пятигорск, 2011. 194 с.

19. Новиков А.М., Новиков Д.А. Методология: словарь системы основных понятий. М.: Либроком, 2013. 208 c.

20. Райзберг Б.А., Лозовский Л.Ш., Стародубцева Е.Б. Современный экономический словарь. 5-е изд, перераб. и доп. М.: ИНФРА-М, 2006.

21. Румянцева Е.Е. Новая экономическая энциклопедия. 4-е изд. М.: ИНФР А-М, 2010.

22. Сатпаев Д. Коррупция в Казахстане и качество государственного управления // Interim Report for Exploring Informal Networks in Kazakhstan: A Multidimensional Approach, IDE-JETRO, 2013. http://www.ide.go.jp/Japanese/Publish/Download/Report /2012/ pdf/ C24_ch3.pdf

23. Саханова Г.Б. Развитие конкурентоспособности экономики Республики Казахстан: проблемы и перспективы (на примере пищевой промышленности): Дисс. PhD. Алматы, 2012. $167 \mathrm{c}$.

24. Скиперская Е.В. Социально-экономическая эффективность функционирования интегрированных структур в АПК: на материалах Ставропольского края: Дисс. ... к.э.н. Ставрополь, 2012. $172 \mathrm{c.}$

25. Структуры поддержки предпринимательства // Сайт АО «Фонд развития предпринимательства «Даму», 2013 http://www.damu.kz/127

26. Сулейменова Г.К. Административные барьеры в развитии предпринимательства (теоретическое осмысление) // Казахстан-Спектр. 2005. №2. с. 91-97

27. Терехова В.А. Зарубежные концепции управленческого учета и российская практика / В.А. Терехова // Экономический анализ. 2010. №1. С. 36-38.

28. Улучшение доступа к финансированию в агропромышленном комплексе Казахстана. Руководство по политике в области развития частного сектора. Фаза 2 проекта «Стратегия повышения отраслевой конкурентоспособности Казахстана». январь 2013 года. 
107 c. // Сайт Организации экономического сотрудничества и развития (ОЭСР)(Тhe Organisation for Economic Cooperation and Development (OECD)), $2013 \mathrm{http}$ ://www.oecd.org/

29. Эмануэль И.В. Развитие вертикально интегрированных структур в агропродовольственном комплексе России: Дисс. ... д.э.н. Саратов, 2012. 384 с.

30. Balakrishnan R. (2008) Managerial Accounting/ R.Balakrishnan, K.Sivaramakrishnan, G.Sprinkle. Hardcover. 704 p.

31. Bennett R. J. (2014) Entrepreneurship, Small Business and Public Policy Evolution and revolution Routledge. 168 p.

32. Bugdol M., Jedynak P. (2014) Integrated Management Systems. Springer International Publishing. 194 p.

33. Drury C. (2012) Management and Cost Accounting. M Com Book. 850 p.

34. Hatten T.S. (2011) Small Business Management: Entrepreneurship and Beyond Hardcover. $260 \mathrm{p}$.

35. Hilmar J.V. (2007) Controlling-Instrumente von A - Z: Die wichtigsten Werkzeuge zur Unternehmenssteuerung Haufe Lexware. 478 p.

36. International Growth of Small and Medium Enterprises (2011) Edited by N. Nummela Routledge .310 p.

37. Jiambalvo J. (2013) Managerial Accounting. John Wiley \& Sons Ltd.August. 544 p.

38. Johnson P. (2008) The Formation and Development of Small Business. Issues and Evidence. Routledge. 256 p.

39. Kaplan R.S., Matsumura E. M. (2011) Management Accounting: Information for Decision-Making and Strategy Execution. M Com Book. 551 p.

40. Longenecker J. G. (2013) Small Business Management / J. G. Longenecker, J. W.Petty, L. E. Palich, F.Hoy Hardcover. 340 p.

41. Noreen E. (2010) Managerial Accounting for Managers / E.Noreen, P. Brewer, R. Garrison. Irwin/McGraw-Hill. 628 p.

42. Pardy W., Andrews T. (2009) Integrated Management Systems: Leading Strategies and Solutions. Hardcover. $280 \mathrm{p}$.

43. Pilot M. J. (2014) Driving Sustainability to Business Success: The DS Factor Management System Integration and Automation. John Wiley \& Sons, Inc. 346 p.

44. Reid G. (2007) The Foundations of Small Business Enterprise. An Entrepreneurial Analysis of Small Firm Inception and Growth. Routledge. 404 p.

45. The Management of Small and Medium Enterprises (2011) Edited by M. Fink, S.Kraus Routledge. $312 \mathrm{p}$.

\section{References:}

1. Programma po razvitiyu agropromyshlennogo kompleksa v Respublike Kazakhstan na 2013-2020 gody (Agrobiznes - 2020). Astana, 2012. 97 S.

2. Rasporyazhenie Prem'er-Ministra Respubliki Kazakhstan ot 7 dekabrya 2012 goda № 226-r «Ob utverzhdenii Plana meropriyatii po podderzhke i razvitiyu pererabotki sel'skokhozyaistvennoi produktsii i pishchevoi promyshlennosti» // IPS "Odilet", http://adilet.zan.kz/rus/docs/R1200000226

3. Belyi E.M., Rozhkova E.V., Tyulin A.E. Integrirovannye struktury v sovremennoi ekonomike: sushchnost', tendentsii razvitiya // Fundamental'nye issledovaniya. 2013. №6. S. 1482-1484. //http://www.rae.ru/fs/?section=content\&op=show_article\&article_id=10000974

4. Bregg S. Nastol'naya kniga finansovogo direktora / Per. s angl. 4-e izd. M.: Al'pina Pablisher, 2013. $608 \mathrm{~s}$.

5. Vasil'eva N.A. Razvitie strategicheskogo potentsiala predpriyatii pishchevoi promyshlennosti Rossii v usloviyakh global'noi konkurentsii: metodologiya, teoriya, praktika: Diss. ... d.e.n. Saratov, 2012. 404 s.

6. Garrison R., Norin E., Bryuer P. Upravlencheskii uchet [Managerial Accounting] / Per s ang. SPb.: Piter, 2013. 592 s.

7. Gurevich L. Kazakhstanskii predprinimatel': samootsenka sobstvennoi istorii, prednaznacheniya i perspektiv// Sait Tsentra biznes-informatsii, sotsiologicheskikh i 
marketingovykh issledovanii BISAM Central Asia http://www.bisam.kz/ research/reports /msb.html

8. Demeuova G.T. Formirovanie i funktsionirovanie sistemy kontrollinga v Kazakhstane: opyt otsenki i rasshirenie ee masshtabov: Avtoreferat diss. ... d.e.n. Almaty, 2010. $47 \mathrm{~s}$.

9. Doklad Prodovol'stvennoi i sel'skokhozyaistvennoi organizatsii OON (FAO) The State of Food Insecurity in the World, 2013 http://www.fao.org/docrep/o18/i3434e/i3434eoo.htm

10. Dostupnost' bankovskogo kreditovaniya v Kazakhstane Otchet po rezul'tatam izucheniya mneniya klientov bankov, 2012 //Sait Tsentra issledovanii Sandzh http://www.sange.kz/files/8413/6022/0568/__ u.pdf

11. Zaporozhtseva L.A. Vnutrennii monitoring finansovoi ustoichivosti sel'skokhozyaistvennykh predpriyatii: formirovanie i razvitie: Diss.... k.e.n. Voronezh, 2007. 212 s.

12. Kazakhstan v 2013 godu. Statisticheskii sbornik /pod red. A.A. Smailova. Astana, 2014. $484 \mathrm{~s}$.

13. Kaigorodtsev A.A. Ekonomicheskaya i prodovol'stvennaya bezopasnost' Kazakhstana. Voprosy teorii, metodologii, praktiki: monografiya. Ust'-Kamenogorsk: Media-Al'yans, 2006. $440 \mathrm{~s}$.

14. Kaminski B., Mitra S. Klubok shelka: bezgranichnye bazary i prigranichnaya torgovlya v Tsentral'noi Azii. Vsemirnyi Bank, 2012. $132 \mathrm{s.}$

15. Karminskii A. M., Fal'ko S. G., Zhevaga A. A., Ivanova N. Yu. Kontrolling. M.,: Forum, 2013. $336 \mathrm{~s}$.

16. Kleiner B.G. Evolyutsiya institutsional'nykh sistem. M.: Nauka, 2009. 240 s. s. 20.

17. Kostenkova V.G. Prodvizhenie na rynke sovremennykh produktov pishchevoi promyshlennosti $\mathrm{v}$ usloviyakh shirokomasshtabnoi ekspansii importnykh tovarov// Vestnik udmurtskogo universiteta. 2009. № 2. s. 63-68

18. Mai-Boroda G.N. Potentsial integratsionnykh obrazovanii kak ob"ektov upravleniya v agropromyshlennom komplekse: Diss. ... k.e.n. Pyatigorsk, 2011. 194 s.

19. Novikov A.M., Novikov D.A. Metodologiya: slovar' sistemy osnovnykh ponyatii. M.: Librokom, 2013. $208 \mathrm{~s}$.

20. Raizberg B.A., Lozovskii L.Sh., Starodubtseva E.B. Sovremennyi ekonomicheskii slovar'. 5-e izd, pererab. i dop. M.: INFRA-M, 2006. 2010.

21. Rumyantseva E.E. Novaya ekonomicheskaya entsiklopediya. 4-e izd. M.: INFR A-M,

22. Satpaev D. Korruptsiya v Kazakhstane i kachestvo gosudarstvennogo upravleniya // Interim Report for Exploring Informal Networks in Kazakhstan: A Multidimensional Approach, IDE-JETRO, 2013. http://www.ide.go.jp/Japanese/Publish/Download/Report /2012/ pdf/ C24_ch3.pdf

23. Sakhanova G.B. Razvitie konkurentosposobnosti ekonomiki Respubliki Kazakhstan: problemy i perspektivy (na primere pishchevoi promyshlennosti): Diss. PhD. Almaty, 2012. $167 \mathrm{~s}$.

24. Skiperskaya E.V. Sotsial'no-ekonomicheskaya effektivnost' funktsionirovaniya integrirovannykh struktur v APK: na materialakh Stavropol'skogo kraya: Diss. ... k.e.n. Stavropol', 2012. $172 \mathrm{~s}$.

25. Struktury podderzhki predprinimatel'stva // Sait AO «Fond razvitiya predprinimatel'stva «Damu», 2013 http://www.damu.kz/127

26. Suleimenova G.K. Administrativnye bar'ery v razvitii predprinimatel'stva (teoreticheskoe osmyslenie) // Kazakhstan-Spektr. 2005. №2. s. 91-97

27. Terekhova V.A. Zarubezhnye kontseptsii upravlencheskogo ucheta i rossiiskaya praktika / V.A. Terekhova // Ekonomicheskii analiz. 2010. №1. S. 36-38.

28. Uluchshenie dostupa k finansirovaniyu v agropromyshlennom komplekse Kazakhstana. Rukovodstvo po politike v oblasti razvitiya chastnogo sektora. Faza 2 proekta «Strategiya povysheniya otraslevoi konkurentosposobnosti Kazakhstana». yanvar' 2013 goda. 107 s. // Sait Organizatsii ekonomicheskogo sotrudnichestva i razvitiya (OESR)(The Organisation for Economic Cooperation and Development (OECD)), 2013 http://www.oecd.org/

29. Emanuel' I.V. Razvitie vertikal'no integrirovannykh struktur v agroprodovol'stvennom komplekse Rossii: Diss. ... d.e.n. Saratov, 2012. 384 S.

30. Balakrishnan R. (2008) Managerial Accounting/ R.Balakrishnan, K.Sivaramakrishnan, G.Sprinkle. Hardcover. 704 p. 
31. Bennett R. J. (2014) Entrepreneurship, Small Business and Public Policy Evolution and revolution Routledge. 168 p.

32. Bugdol M., Jedynak R. (2014) Integrated Management Systems. Springer International Publishing. $194 \mathrm{r}$.

33. Drury C. (2012) Management and Cost Accounting. M Com Book. 850 p.

34. Hatten T.S. (2011) Small Business Management: Entrepreneurship and Beyond Hardcover. $260 \mathrm{r}$.

35. Hilmar J.V. (2007) Controlling-Instrumente von A - Z: Die wichtigsten Werkzeuge zur Unternehmenssteuerung Haufe Lexware. $478 \mathrm{r}$.

36. International Growth of Small and Medium Enterprises (2011) Edited by N. Nummela Routledge .310 p.

37. Jiambalvo J. (2013) Managerial Accounting. John Wiley \& Sons Ltd.August. 544 r.

38. Johnson P. (2008) The Formation and Development of Small Business. Issues and Evidence. Routledge. 256 p.

39. Kaplan R.S., Matsumura E. M. (2011) Management Accounting: Information for Decision-Making and Strategy Execution. M Com Book. 551 p.

40. Longenecker J. G. (2013) Small Business Management / J. G. Longenecker, J. W.Petty, L. E. Palich, F.Hoy Hardcover. 340 r.

41. Noreen E. (2010) Managerial Accounting for Managers / E.Noreen, P. Brewer, R. Garrison. Irwin/McGraw-Hill. 628 p.

42. Pardy W., Andrews T. (2009) Integrated Management Systems: Leading Strategies and Solutions. Hardcover. $280 \mathrm{r}$.

43. Pilot M. J. (2014) Driving Sustainability to Business Success: The DS Factor Management System Integration and Automation. John Wiley \& Sons, Inc. 346 r.

44. Reid G. (2007) The Foundations of Small Business Enterprise. An Entrepreneurial Analysis of Small Firm Inception and Growth. Routledge. 404 p.

45. The Management of Small and Medium Enterprises (2011) Edited by M. Fink, S.Kraus Routledge. 312 p. 